\title{
USUÁRIOS SURDOS E ACESSIBILIDADE EM BIBLIOTECAS: UMA REVISÃO DA LITERATURA CIENTÍFICA BRASILEIRA
}

\author{
DEAF USERS AND ACCESSIBILITY IN LIBRARY: A \\ REVIEW OF BRAZILIAN SCIENTIFIC LITERATURE
}

Sylvana Karla da Silva de Lemos Santosa

\begin{abstract}
RESUMO
Introdução: as novas tecnologias e a internet promovem mudanças no acesso à informação e na comunicação entre os sujeitos. Os usuários surdos são considerados parte de um público que carece de atenção para atender as suas necessidades informacionais. Objetivo: apresentar uma revisão de literatura de publicações brasileiras que abordam a relação entre usuário Surdo e a biblioteca caracterizada pela acessibilidade à informação e à comunicação. Metodologia: pesquisa exploratória e bibliográfica. Resultados: quantidade escassa de publicações com abordagem no tema tratado. Conclusões: necessidade de maior difusão da cultura e da língua de sinais em espaços formais e não formais para promover o atendimento ao usuário Surdo em sua primeira língua.
\end{abstract}

Descritores: Surdos. Acessibilidade. Bibliotecas. Revisão de literatura.

\section{INTRODUÇÃO}

Em um cenário de novas tecnologias que se apresentam sob diferentes modalidades e a conectividade pela internet, torna-se importante investigar ações que promovem a acessibilidade de usuários no espaço físico e virtual de bibliotecas. Dentre os perfis de usuários a serem considerados encontra-se o Surdo1, que é comumente considerado parte de uma minoria linguística (CHALHUB; GOMES, 2018) e de uma minoria social (MIGLIOLI; SANTOS, 2017)

\footnotetext{
a Doutora em Ciência da Informação pela Universidade de Brasília. Docente do eixo Informação e Comunicação no Instituto Federal de Brasília. E-mail: sylkarla@gmail.com.

${ }^{1}$ Felipe (2007, p. 33) enfatiza que a palavra Surdo(a) é grafada com "S" maiúsculo para "indicar que se trata de uma pessoa que luta por seus direitos políticos, linguísticos e culturais, ou seja, pessoa que faz parte de uma comunidade surda" e é usuária da Língua Brasileira de Sinais Libras. Esta investigação fará uso desse padrão de grafia como forma de enfatizar as características do principal sujeito da pesquisa.
} 
sendo, portanto, o sujeito de interesse desta pesquisa.

Segundo Akaichi et al. (2013, p. 32-33), "a expansão das práticas de comunicação, mediadas pelas tecnologias da informação e comunicação, traz mudanças significativas no contexto sociocultural”. Neste sentido, mostra-se importante que a biblioteca e seus colaboradores conheçam as características de seus usuários e suas preferências de acesso à informação.

Sanz Casado (1993) ressalta as mudanças ocorridas no final do Século XX nas atividades humanas e na sociedade, com a geração de informação científica em crescimento exponencial que necessita de divulgação rápida pelo uso de ferramentas tecnológicas. No entanto, o autor pondera que é preciso ter uma gestão adequada para que a quantidade crescente de documentos seja oferecida aos usuários que dela necessitarem.

A relevância do estudo de usuários, considerado um dos campos de pesquisa da Ciência da Informação $(\mathrm{Cl})$, está em conhecer quem é esse indivíduo, quais as suas necessidades de informação, como a utilizam e quais seus comportamentos de busca (KAFURE et al., 2013). Investigações voltadas a essa temática possibilitam planejar serviços adequados para atender às necessidades da maioria dos usuários, seja numa biblioteca física ou pelo uso de um sistema de informação (CUNHA, 1999; 2008).

No caso dos usuários Surdos, é primordial enfatizar a diferença linguística e cultural desses indivíduos, em oposição ao discurso de normalização e de medicalização do que trata a "pessoa com surdez" (PIVETTA; SAITO; ULBRICHT, 2014), que está relacionado a uma concepção patológica, algo que foge à normalidade, caracterizando-a como incapaz (MARTINS; LINS, 2015). Assim, embora a legislação brasileira ainda trate em sua redação do termo "pessoa com deficiência auditiva", aqui será evidenciado o Surdo ao preconizar aquele que faz uso da Língua de Sinais como primeira língua (L1) e da língua escrita como segunda língua (L2).

Este artigo busca apresentar uma revisão de literatura das publicações brasileiras que abordam a relação entre usuário Surdo e a biblioteca caracterizada pela acessibilidade à informação e à comunicação. 


\section{USUÁRIO SURDO}

Dados do Censo do Instituto Brasileiro de Geografia e Estatística (IBGE) de 2010 apontam que quase um quarto da população residente no país (23,9\%) possuíam pelo menos uma das deficiências investigadas na pesquisa: visual, auditiva e motora, representadas como limitações sensoriais, e deficiência mental ou intelectual (BRASIL, 2012, p. 6).

$\mathrm{Na}$ era da inclusão, o conceito de deficiência, segundo Sassaki (2002), passou por mudanças de valores com novos significados para dar origem a novos conceitos sociais. Alguns termos, historicamente utilizados de forma pejorativa e preconceituosa para fazer referência a pessoas com limitações diversas, estão sendo atualizados para Pessoa com Deficiência, de acordo com o que foi adotado pela Convenção sobre os Direitos da Pessoa com Deficiência, em 2006, da qual o Brasil é signatário (BRASIL, 2009).

Dentre as deficiências consideradas sensoriais, encontra-se a deficiência auditiva que está relacionada com a perda sensorial da audição e cujas causas podem ser congênitas, desde o nascimento, ou adquiridas ao longo da vida (SONZA; FÉO; PAGANI, 2013). A fase da vida em que ocorre a perda auditiva pode interferir na aquisição da linguagem, caso seja antes do letramento do indivíduo, e comprometer a oralidade e a compreensão. Dessa forma, o atendimento a estas pessoas pode variar de acordo com a necessidade e 0 contexto em que estão habituadas.

De acordo com as metodologias de ensino das pessoas com deficiência auditiva (SONZA; FÉO; PAGANI, 2013), tem-se: Oralismo, Comunicação Total e Bilinguismo. Aqueles que fazem uso do Oralismo, frequentemente, convivem com pessoas não surdas, favorecendo o desenvolvimento da linguagem oral, conseguem fazer a leitura labial ${ }^{2}$, além de auxiliar no reconhecimento de sons. Muitas dessas fazem uso de prótese auditiva como ferramenta para amplificar os sons. Indivíduos que fazem uso da Comunicação Total utilizam gestos

\footnotetext{
${ }^{2}$ Leitura labial ou leitura da fala, consiste na interpretação visual da comunicação de um falante através da decodificação dos movimentos dos lábios e das expressões fornecidas pela contração dos músculos da face (ABNT NBR 15599, 2008, p. 3).
} 
naturais, português sinalizado3, língua de sinais, leitura labial e alfabeto datilológico4. Estas técnicas contribuem para o desenvolvimento da linguística e favorecem à comunicação. Por fim, o Bilinguismo assume a Língua de Sinais como primeira língua (L1) e a língua oficial do país, na forma escrita, como segunda (L2), presentes de forma simultânea no processo educacional.

A diferença linguística é o que caracteriza o Surdo como membro de uma comunidade e detentor de uma cultura e de uma identidade própria. Essa cultura apresenta características que são específicas, sendo ela visual e que se traduz de forma visual, recebida pelos olhos e produzidas pelas mãos (QUADROS; 2004; QUADROS; KARNOPP, 2004). Importante ressaltar que há Línguas de Sinais próprias de cada país e, no caso do Brasil, é por meio da Libras, oficialmente reconhecida como meio legal de comunicação e expressão (BRASIL, 2002) que os Surdos interagem.

\section{ACESSIBILIDADE}

A palavra acessibilidade vem do latim accessibilitas e remete ao que pode ser alcançado, compreendido, tem facilidade na aproximação, no tratamento ou na aquisição (DICIONÁRIO HOUAISS, 2018). Em uma abordagem ampla, a acessibilidade ainda é frequentemente relacionada a questões físicas, como a existência de rampas para o atendimento às pessoas com mobilidade reduzida. No entanto, é importante ampliar seu conceito no sentido de permitir o atendimento às necessidades das pessoas com deficiência, idosas, gestantes, lactantes, dentre outras com carências permanentes ou temporárias (BRASIL, 2009).

O Brasil, como nação membro da ONU, incorporou a Convenção sobre os Direitos das Pessoas com Deficiência (BRASIL, 2012) à legislação brasileira em 2009, tendo efeito de emenda constitucional, e reconheceu um instrumento

\footnotetext{
${ }^{3}$ Português sinalizado corresponde a realizar os sinais na estrutura do português (MARQUES, 2007, p. 142).

${ }^{4}$ Alfabeto datilológico representa a escrita de palavras ou parte de palavras da forma gráfica das letras das diferentes línguas orais para configurações de mãos das diferentes línguas de sinais (FARIA-NASCIMENTO, 2009, p. 62).
} 
que gera maior respeito aos Direitos Humanos. Este documento trata em seu Art. 9ำ sobre Acessibilidade, em cujo parágrafo destaca:

\begin{abstract}
A fim de possibilitar às pessoas com deficiência viver de forma independente e participar plenamente de todos os aspectos da vida, os Estados Partes tomarão as medidas apropriadas para assegurar às pessoas com deficiência o acesso, em igualdade de oportunidades com as demais pessoas, ao meio físico, ao transporte, à informação e comunicação, inclusive aos sistemas e tecnologias da informação e comunicação, bem como a outros serviços e instalações abertos ao público ou de uso público, tanto na zona urbana como na rural (BRASIL, 2009).
\end{abstract}

Em seu Art. 21, o Decreto № 6.949 (BRASIL, 2009) trata do acesso à informação e atribui aos Estados Partes a responsabilidade de assegurar às pessoas com deficiência o exercício do seu direito à liberdade de buscar, receber e compartilhar informações e ideias, em igualdade de oportunidades com as demais pessoas, garantindo a mediação da comunicação na forma de sua escolha. Destaca-se no contexto dos itens (a), (d) e (e) do referido Decreto, respectivamente, o atendimento imediato e sem custo adicional para 0 fornecimento de informações "em formatos acessíveis e tecnologias apropriadas aos diferentes tipos de deficiência"; o incentivo da mídia e dos provedores de Internet para tornar seus serviços acessíveis a pessoas com deficiência; e o reconhecimento e a promoção do uso de línguas de sinais. Nestes termos, a legislação permite abarcar o propósito para o qual se destina, que é "promover, proteger e assegurar o exercício pleno e equitativo de todos os direitos humanos".

A Lei da Acessibilidade, Lei nº 10.098/2000 (BRASIL, 2000) estabelecia normas gerais e critérios básicos para a promoção da acessibilidade das pessoas portadoras de deficiência ou com mobilidade reduzida. Em 2015, a partir da redação e publicação da Lei no 13.146, conhecida como Lei Brasileira da Inclusão (LBI) ou Estatuto da Pessoa com Deficiência (BRASIL, 2015), foram incluídos conceitos emergentes acerca da pessoa com deficiência, como desenho universal e tecnologia assistiva ou ajuda técnica. A definição de acessibilidade, conforme o Art. 3ํㅡ da referida Lei, passa a ser dada como:

Possibilidade e condição de alcance para utilização, com segurança e autonomia, de espaços, mobiliários, equipamentos urbanos, edificações, transportes, informação e comunicação, inclusive seus sistemas e tecnologias, bem como de outros 
serviços e instalações abertos ao público, de uso público ou privados de uso coletivo, tanto na zona urbana como na rural, por pessoa com deficiência ou com mobilidade reduzida (grifo nosso).

Destaca-se a presença dos sistemas e das tecnologias, na ênfase dada ao parágrafo citado, de modo que esta Lei estabelece ao Poder Público promover a eliminação de barreiras para garantir o "direito de acesso à informação, à comunicação, ao trabalho, à educação, ao transporte, à cultura, ao esporte e ao lazer". Nesse contexto, sobressai o direito ao acesso à informação e à educação que pode ser associado ao uso efetivo das TIC.

Sob a perspectiva arquitetônica, a acessibilidade é descrita pela Norma Brasileira NBR-9050 (ABNT, 2004) que trata da acessibilidade relacionada a edificações, mobiliários, espaços e equipamentos urbanos. A versão de 2004 trazia a concordância entre os termos "pessoa com deficiência" e "pessoa com surdez". Já em sua nova redação, a NBR 9050/2015 (ABNT, 2015, p. 2) traz a descrição do termo Acessibilidade como:

Possibilidade e condição de alcance, percepção e entendimento para utilização, com segurança e autonomia, de espaços, mobiliários, equipamentos urbanos, edificações, transportes, informação e comunicação, inclusive seus sistemas e tecnologias, bem como outros serviços e instalações abertos ao público, de uso público ou privado de uso coletivo, tanto na zona urbana como na rural, por pessoa com deficiência ou mobilidade reduzida (grifo nosso).

A nova versão da NBR 9050 se mostra mais abrangente pelo acréscimo dos termos "percepção e entendimento de utilização", o que remete aos aspectos do desenho universal e à adoção de uma linguagem clara e comum. Constatase, ainda, a ampliação do conceito de acessibilidade na referida redação, ao incluir a possibilidade de utilização em "transportes, informação e comunicação, inclusive seus sistemas e tecnologias" na zona urbana e rural (CIANTELLI; LEITE, 2016, p. 421).

Símbolos internacionais são recomendados por instituições normativas como forma de padronizar a identificação em locais, equipamentos, produtos, procedimentos ou serviços destinados para pessoa com deficiência auditiva, como mostra a Figura 1a. No caso da identificação visual de conteúdos e serviços disponíveis em Libras, foi criado o símbolo "Acessível em Libras" 
(UNIVERSIDADE..., 2013), que pode ser comumente encontrado em sítios web, geralmente no canto superior direito, o que indica que possuem conteúdo acessível em Libras (Figura 1b). Desde 2015, a Organização das Nações Unidas (ONU) criou a logomarca "A Acessibilidade" (The Accessibility) com o objetivo de simbolizar a esperança e a igualdade de acesso a todos e para aumentar a consciência sobre o universo das pessoas com deficiência em todos os lugares. A Figura 1c mostra o logotipo que representa a harmonia entre o ser humano e a sociedade e, com os braços abertos, simboliza a inclusão de pessoas com todas as habilidades (INCLUSIVE..., 2015).

Figura 1 - Símbolo internacionais: (a) pessoa com deficiência auditiva; (b) Acessibilidade em Libras e (c) "A Acessibilidade".

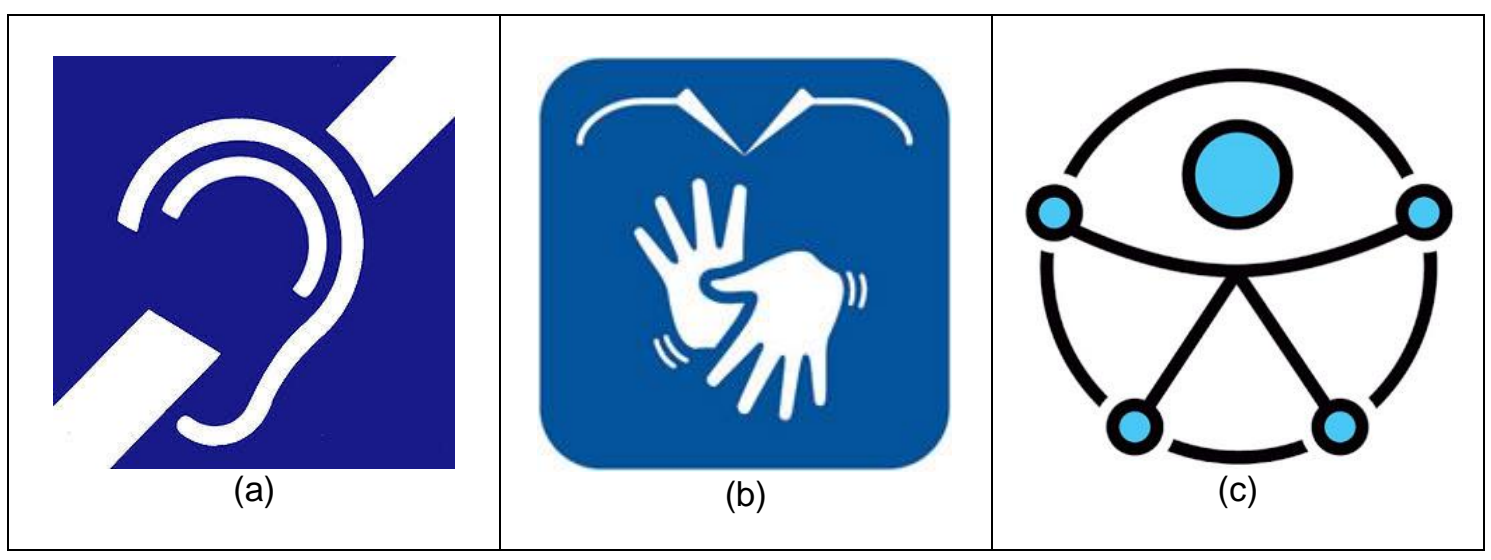

Fonte: ABNT NBR 9050 (2004, p. 20); Universidade... (2013); Inclusive... (2015).

Percebe-se que, as peças visuais descritas anteriormente, são como frutos de uma evolução cronológica, histórica e social, de modo a incorporar conceitos emergentes no que diz respeito à inclusão da pessoa com deficiência.

O Manual de Acessibilidade em Documentos Digitais, publicado em 2017, aponta as principais barreiras enfrentadas no meio digital pela pessoa com deficiência auditiva: (1) Áudio que não oferece opção para aumentar o volume; (2) Áudio e vídeo sem legenda, transcrição em texto e Libras; (3) Ausência de Libras ou imagens suplementares relacionadas ao conteúdo do texto (isso dificulta a compreensão por pessoas que têm a Libras como primeira língua); (4) Ausência de linguagem simples e clara (SALTON; DALL AGNOL; TURCATTI, 2017, p. 26).

Torres, Mazzoni e Alves (2002, p. 83) destacam que a acessibilidade é 
"um processo dinâmico, associado não só ao desenvolvimento tecnológico, mas principalmente ao desenvolvimento da sociedade", sendo um conceito que aborda tanto os aspectos do espaço físico em que vivemos, como do espaço digital. Dessa forma, a implantação de requisitos de acessibilidade precisa contribuir para a inclusão das pessoas no desenvolvimento das atividades relacionadas ao labor, ao lazer e à cultura, assim como para o exercício do seu direito de escolha política.

No contexto da inclusão social, a acessibilidade é abordada para permitir que as pessoas com limitações sensoriais possam ter acesso a bens culturais. Para tanto, faz-se necessária a implementação de estratégias de mediação para ampliar o uso dos canais de percepção não somente verbal (oral e escrita), mas de forma interativa e experimental (TOJAL, 2014). No caso de peças de teatro, por exemplo, a acessibilidade pode ser viabilizada pela atuação de um intérprete de Língua de Sinais na mediação do conteúdo para Surdos e usuários da Libras.

Neste sentido, e de acordo com Miglioli e Santos (2017, p. 137), "o acesso à informação é vital para um indivíduo participar plenamente na sociedade, e o oposto também é verdadeiro - a falta de informação contribui para a exclusão social". Assim, prover acessibilidade implica em garantir que todas as pessoas possam interagir de maneira efetiva com a informação e a comunicação.

\section{PROCEDIMENTOS METODOLÓGICOS}

A pesquisa possui caráter exploratório e bibliográfico com realização de levantamento bibliográfico para identificar publicações que associem o conceito da acessibilidade ao usuário Surdo e sua interação com a informação e a comunicação em bibliotecas. Segundo Flick (2009, p. 65), a pesquisa bibliográfica permite "analisar alguns periódicos adequados e observar o que foi publicado nos últimos anos".

A revisão de literatura teve início pela busca por trabalhos científicos, considerando os principais periódicos da Ciência da Informação existentes no cenário brasileiro, especialmente aqueles ligados a programas de pósgraduação, que promovem a divulgação gratuita e on-line. A consulta considerou os termos "acessibilidade", "surdo" e "biblioteca", exclusivamente em língua 
portuguesa, sem distinção de Qualis e ano de publicação. A partir do acesso à página web de 20 periódicos científicos em atividade no Brasil, foram encontrados apenas cinco artigos ${ }^{5}$. Diante deste pequeno quantitativo e de forma a ampliar o universo de busca da pesquisa, foram consultadas outras bases de dados, como a Base de Dados de Teses e Dissertações (BDTD) e o Repositório Digital Huet ${ }^{6}$ do Instituto Nacional de Educação de Surdos (INES). No entanto, o levantamento alcançou o total de sete publicações, com o acréscimo de uma pesquisa de pós-graduação e um trabalho apresentado em evento.

\section{APRESENTAÇÃO E DISCUSSÃO DOS RESULTADOS}

Para iniciar este tópico, julgou-se relevante contextualizar historicamente a evolução das bibliotecas no contexto das tecnologias, o acesso à informação e os usuários na Ciência da Informação (Cl). Na abordagem de Cunha (1999), as bibliotecas denominadas convencionais ou tradicionais são aquelas em que seu acervo é composto por documentos em papel. Com a invenção da imprensa e a revolução no âmbito da biblioteca no final do século XIX, o catálogo em livro foi substituído pelo catálogo em fichas. Em seguida, as bibliotecas implementaram o catálogo em linha, com o acesso a bancos de dados, uso do periódico eletrônico, acesso a textos e itens de outras fontes de referência (CUNHA, 2008).

Com a chegada da Internet ao Brasil e o advento da web, as formas para acessar e recuperar a informação aumentaram consideravelmente. A informação em formato digital e descentralizada ampliava as possibilidades de serem acessadas remotamente, oferecendo ao usuário da biblioteca opções para consultar e alcançar o que era desejado. As características de uma biblioteca digital possuem semelhanças com a biblioteca convencional, destacando-se a mudança na representação digital da informação devido à implementação de recursos da informática (CUNHA, 2008).

\footnotetext{
${ }^{5}$ Busca realizada entre os dias 13 e 16 de janeiro de 2020, a partir do navegador e buscador Google Chrome ${ }^{\circledR}$.

${ }^{6}$ Repositório Digital Huet. Disponível em: http://repositorio.ines.gov.br/ilustra/. Acesso: 14 jan. 2020.
} 
Para os bibliotecários, trata-se de um cenário de avanço com a tecnologia que possibilitou um trabalho mais fácil e rápido (CUNHA, 2008). Aliado a isso, "muitas das informações que eram disseminadas no meio físico passaram para o meio eletrônico, devido à facilidade que a web trouxe à veiculação de informações" (FERREIRA; CRUZ; SANTOS, 2017, p. 12). Cabe destacar que ter o "acesso à informação" é diferente de ter uma "informação acessível", o que levou à preocupação de pesquisadores em estudar sobre essa temática no ambiente da biblioteca, incluindo usuários com deficiência auditiva e Surdos.

A Federação Internacional de Associações e Instituições de Bibliotecas IFLA (International Federation of Library Associations and Institutions) publicou em 2000 um documento chamado Diretrizes para Serviços de Bibliotecas para Surdos (DSBS), com o intuito de informar aos bibliotecários sobre as necessidades dos usuários Surdos em relação às bibliotecas e à informação, alertando que todas as bibliotecas têm Surdos como uma parcela de seus usuários (IFLA, 2000).

Por vários motivos, a maioria das bibliotecas não tem considerado a atenção especial à oferta de serviços para as pessoas que são surdas. A surdez tem sido chamada como "deficiência invisível" porque as pessoas surdas não são identificadas como surdas por falta de observação. [...] Além disso, as pessoas que são surdas congênitas ou desde muito pequenas têm, frequentemente, dificuldades para ler e, por consequência, não usam a biblioteca (IFLA, 2000, p. 9).

Apesar desse fato, felizmente, contatou-se que pesquisas realizadas na última década vêm relatando ações cujo intuito é promover a acessibilidade no ambiente das bibliotecas, tanto físicas quanto digitais, a fim de incluir o usuário Surdo na biblioteca.

Gomes (2013) buscou analisar a inclusão do Surdo em ambientes virtuais e a presença dos padrões de acessibilidade e usabilidade como requisitos essenciais para alcançar o direito à informação deste sujeito, enquanto cidadão. Para tanto, a autora investigou questões relacionadas à aquisição da linguagem da leitura, do domínio da escrita, da alfabetização e do letramento para enfatizar a dificuldade encontrada pelo Surdo tanto em ambientes físicos quanto virtuais. A pesquisa tomou como objeto os ambientes virtuais de 51 bibliotecas universitárias federais brasileiras, a fim de verificar se estes viabilizam a 
interação do usuário com a interface dos seus sítios web, segundo as recomendações de acessibilidade e heurísticas de usabilidade (GOMES, 2013). A pesquisa promove, ainda, a discussão sobre questões desafiadoras, como a competência do profissional da biblioteca para utilizar o sistema da biblioteca e para atender o usuário Surdo em suas necessidades.

O estudo de Galvão, Santos e Santos (2014) apresenta ações que uma biblioteca pública estadual tem realizado em prol da acessibilidade da criança e do adolescente Surdo. As autoras identificaram ações como: a oferta de serviços e produtos na Libras por meio de ações culturais e educativas, oficinas e cursos. Os resultados mostram que as barreiras que este público enfrenta na busca da informação na biblioteca podem ser minimizadas. Como exemplo, a partir da participação da comunidade externa em um curso de Libras ofertado anualmente, foi possível promover a disseminação da língua e aproximar a comunidade do público Surdo, desmistificando questões sociais com o conhecimento adquirido sobre a língua. Concluiu-se que estas ações proporcionam acessibilidade e inclusão do Surdo, por meio do acesso ao livro e à leitura, estando de acordo com a legislação da acessibilidade e da Libras (GALVÃO; SANTOS; SANTOS, 2014).

Miranda e Miranda (2015) realizaram um estudo considerando as ações voltadas para o atendimento à pessoa com deficiência auditiva e ao Surdo pelo uso do Sistema de Bibliotecas da Unirio - Universidade Federal do Estado do Rio de Janeiro, denominado UNIBIBLI. O estudo buscou verificar se as recomendações das DSBS da IFLA são adotadas pelo sistema das bibliotecas da Unirio, além de investigar a existência de uma política de acessibilidade voltada aos usuários em questão daquela universidade e identificar quais os parâmetros de acessibilidade adotados pelas bibliotecas analisadas com foco no público estudado. Os resultados indicaram que o sistema ora mencionado não possui uma política de acessibilidade que atenda aos usuários Surdos e com deficiência auditiva, e adota parcialmente os itens recomendados pela DSBS (MIRANDA; MIRANDA, 2015, p. 14). No entanto, os participantes da pesquisa demonstraram interesse em realizar adequações necessárias para atender às recomendações. 
Os resultados obtidos na pesquisa de Miranda e Miranda (2015) foram retomados dois anos depois para identificar se o sistema UNIBIBLI cumpriu as adequações realizadas. Foi constatado que, apesar do pouco tempo para implementação (dois anos), o sistema utilizado nas bibliotecas da Unirio conseguiu implantar medidas que irão contribuir para o auxílio aos usuários Surdos. Além disso, as autoras relatam que existem outras ações em andamento ou programadas para o aprimoramento do sistema, o que demonstra 0 compromisso com a acessibilidade para pessoas com deficiência auditiva e Surdas (MIRANDA; COSTA; SILVA, 2017).

O relato de experiência de Miglioli e Santos (2017) empenhou-se em discutir a acessibilidade para Surdos na biblioteca do Instituto Nacional de Educação de Surdos (INES), criado no século XIX e em atividade no Rio de Janeiro, Brasil. O INES foi uma das primeiras instituições brasileiras voltadas à educação de Surdos e possui uma biblioteca que oferece serviços em Libras, graças à formação fornecida aos bibliotecários, dando eficácia ao atendimento e reconhecendo "como espaço identitário e de liberdade pelo público surdo" (MIGLIOLI; SANTOS, 2017, p. 138). As autoras enfatizam a importância de a biblioteca participar de eventos onde haja a presença de minorias sociais e grupos marginalizados, de forma a mostrar-se disponível para criar vínculos com os membros destes subgrupos e, assim, conhecer suas necessidades para melhor atendê-los. Assim, conclui-se que o grande diferencial da biblioteca do INES é atender, prioritariamente, o usuário Surdo em sua primeira língua, que é a Libras, para que este tenha autonomia e perceba a biblioteca como um espaço ao qual pertence.

Santos, Silva e Kafure (2019) buscaram conhecer os hábitos das pessoas com deficiência e as principais tecnologias utilizadas no processo de busca e recuperação da informação. A pesquisa incluiu a participação de dois estudantes Surdos de uma instituição de ensino da Rede Federal de Educação Profissional e Tecnológica (EPT), além da contribuição de servidores da biblioteca quanto ao atendimento a estes usuários. Constatou-se que algumas ferramentas computacionais, como softwares conversores Libras-Português, são utilizadas pelos Surdos para proporcionar a comunicação com outras pessoas Surdas ou 
não surdas a partir de um avatar. Ressalta-se a dificuldade que os Surdos encontram para compreender textos escritos em língua portuguesa, visto que esta é sua segunda língua. Dentre as fontes de informação mais utilizadas, encontra-se o livro e as redes sociais, como o Facebook (SANTOS; SILVA; KAFURE, 2019, p. 137). Na percepção dos servidores da biblioteca, a comunicação com o usuário Surdo é a principal dificuldade encontrada para prover a interação, contudo fica evidente que, apesar da barreira comunicacional, os servidores empregam esforços para atender as necessidades do público Surdo e prover a comunicação, ainda que seja na forma escrita em com a leitura labial.

O último trabalho encontrado versa sobre o caráter digital e inclusivo do Repositório Digital Huet para o atendimento com acessibilidade ao usuário Surdo (PAIVA et al., 2019). Trata-se do primeiro repositório bilíngue Português-Libras do Brasil, desenvolvido para atender aos Surdos e pessoas que trabalham com educação de Surdos. Segundo os autores, é um importante canal para mediação entre os usuários e as informações, pois permite a "recuperação e disseminação de objetos de aprendizagem para alunos surdos e ouvintes em cursos online e presenciais em níveis diversos de ensino" (PAIVA et al., 2019, p. 112). Por seu caráter bilíngue, percebe-se que o ambiente consegue atender aos demais usuários leitores da língua portuguesa tornando-se, assim, inclusivo.

O Quadro 1 mostra, de forma sintetizada, os principais pontos discutidos nas publicações encontradas para o atendimento ao usuário Surdo em bibliotecas.

Quadro 1 - Síntese das publicações investigadas.

\begin{tabular}{|c|c|}
\hline Autores & $\begin{array}{l}\text { Principais pontos de discussão apresentados } \\
\text { nas publicacões }\end{array}$ \\
\hline Gomes (2013) & $\begin{array}{l}\text { Análise da usabilidade em ambientes virtuais de } \\
\text { bibliotecas }\end{array}$ \\
\hline $\begin{array}{l}\text { Galvão, Santos e Santos } \\
\text { (2014) }\end{array}$ & $\begin{array}{l}\text { Promoção da acessibilidade por uma biblioteca } \\
\text { pública estadual em favor da criança e do } \\
\text { adolescente Surdo }\end{array}$ \\
\hline $\begin{array}{l}\text { Miranda e Miranda } \\
\text { (2015) } \\
\text { Miranda, Costa e Silva } \\
(2017)\end{array}$ & $\begin{array}{l}\text { Verificar a existência e implementação de } \\
\text { critérios de acessibilidade ao usuário Surdo em } \\
\text { um sistema de bibliotecas }\end{array}$ \\
\hline
\end{tabular}




\begin{tabular}{|l|l|}
\hline Miglioli e Santos (2017) & $\begin{array}{l}\text { Apresentar o funcionamento de uma biblioteca } \\
\text { pública com o atendimento ao Surdo } \\
\text { prioritariamente em Libras }\end{array}$ \\
\hline $\begin{array}{l}\text { Santos, Silva e Kafure } \\
(2019)\end{array}$ & $\begin{array}{l}\text { Descrever as práticas informacionais e as } \\
\text { barreiras de comunicação com Surdos em uma } \\
\text { biblioteca pública da Rede Federal EPT }\end{array}$ \\
\hline Paiva et al. (2019) & $\begin{array}{l}\text { Apresentar o Repositório Digital Huet como } \\
\text { espaço bilíngue Português-Libras }\end{array}$ \\
\hline
\end{tabular}

Fonte: Elaborado pela autora (2020).

A partir dos pontos destacados no Quadro 1, é possível identificar algumas ações realizadas pelas bibliotecas direcionadas ao atendimento de um público específico, que é o Surdo. Depreende-se das abordagens algumas atitudes com foco na acessibilidade informacional, em ambiente físico ou digital, e na acessibilidade comunicacional com a capacitação de servidores para a aprendizagem da Libras, ressaltando a primeira língua do Surdo. Além disso, evidencia-se a importância para o desenvolvimento de materiais acessíveis para atender leitores da língua portuguesa e usuários da Libras em um ambiente digital e inclusivo.

\section{CONSIDERAÇÕES FINAIS}

Embora quantitativamente pouco expressiva, infere-se que a quantidade de estudos encontrados demonstra uma preocupação de pesquisadores em abordar a temática da acessibilidade para Surdos no contexto das bibliotecas, seja pela ação humana ou pelo uso de sistemas de informação específicos. Além disso, as iniciativas apresentadas no sentido de promover a capacitação dos profissionais e da comunidade para o aprendizado da Libras, primeira língua do usuário, são consideradas promissoras para oportunizar a inclusão dos sujeitos da pesquisa.

Considerando que a Libras é uma língua oficialmente reconhecida pela legislação brasileira e que se apresenta em um cenário de crescente disseminação nas instituições de educação, pondera-se ser pertinente a criação de mais ações com o intuito de difundir a Cultura Surda e a Língua Brasileira de Sinais em outros espaços, incluindo os não formais, de modo que a comunicação e a informação sejam impulsionadas. Dessa forma, espera-se que o público Surdo, considerado "invisível", tenha sua identidade reconhecida, principalmente 
no ambiente da biblioteca no qual a informação deve ser disponibilizada e acessada por todos, sem distinção.

\section{REFERÊNCIAS}

AKAICHI, T.; MANABE, V. M. M. L.; BARTALO, L.; ARAÚJO, C. A. A.

Comportamento informacional no uso de sistemas de informação: o caso do SICOR. Biblos: Revista do Instituto de Ciências Humanas e da Informação, Rio Grande, v. 27, n. 2, p. 31-46, jul./dez. 2013.

ASSOCIAÇÃO BRASILEIRA DE NORMAS TÉCNICAS. NBR 9050:2004.

Acessibilidade a edificações, mobiliário, espaços e equipamentos urbanos. Rio de Janeiro: ABNT, 2004.

ASSOCIAÇÃO BRASILEIRA DE NORMAS TÉCNICAS. NBR 9050:2015.

Acessibilidade a edificações, mobiliário, espaços e equipamentos urbanos. Rio de Janeiro: ABNT, 2015.

ASSOCIAÇÃO BRASILEIRA DE NORMAS TÉCNICAS. NBR 15599.

Acessibilidade - comunicação na prestação de serviços. Rio de Janeiro: ABNT, 2008.

BRASIL. Convenção sobre os Direitos das Pessoas com Deficiência. 4a Edição Revista e Atualizada. Brasília, 2012. Disponível em:

http://www.pessoacomdeficiencia.gov.br/app/sites/default/files/publicacoes/conv encaopessoascomdeficiencia.pdf . Acesso em: 21 jul.2017.

BRASIL. Decreto oㅜ 6.949, de 25 de agosto de 2009. Promulga a Convenção Internacional sobre os Direitos das Pessoas com Deficiência e seu Protocolo Facultativo, assinados em Nova York, em 30 de março de 2007. Diário Oficial [da] República Federativa do Brasil, Poder Legislativo, Brasília, DF, 26 ago. 2009. Seção 1, p. 3. Disponível em:

http://www.planalto.gov.br/ccivil_03/_ato2007-2010/2009/decreto/d6949.htm. Acesso em: 15 jan. 2020.

BRASIL. Lei no 10.098, de 19 de dezembro de 2000. Estabelece normas gerais e critérios básicos para a promoção da acessibilidade das pessoas portadoras de deficiência ou com mobilidade reduzida, e dá outras providências. Câmara dos Deputados. Disponível em: https://www2.camara.leg.br/legin/fed/lei/2000/lei-10098-19-dezembro-2000377651-publicacaooriginal-1-pl.html. Acesso em: 02 jun. 2020.

BRASIL. Lei oㅜ 10.435, de 24 de abril de 2002. Dispõe sobre a transformação da Escola Federal de Engenharia de Itajubá em Universidade Federal de Itajubá - UNIFEI e dá outras providências. Diário Oficial [da] República

Federativa do Brasil, Poder Legislativo, Brasília, DF, 25 abr. 2002. Seção 1, p. 23. Disponível em: 
http://pesquisa.in.gov.br/imprensa/jsp/visualiza/index.jsp?jornal=1\&pagina=23\& data=25/04/2002. Acesso em: 16 jan. 2017.

BRASIL. Lei no 13.145, de 06 de julho de 2015. Denomina "Rodovia Governador Alberto Silva" o trecho da rodovia BR-343 compreendido entre as localidades de Luís Correia e Bertolínia, no Estado do Piauí. Diário Oficial [da] República Federativa do Brasil, Poder Executivo, Brasília, DF, 07 jul. 2015. Seção 1, p. 2. Disponível em: http://pesquisa.in.gov.br/imprensa/jsp/visualiza/index.jsp?jornal=1\&pagina=2\&d ata=07/07/2015. Acesso em: 09 jun.2018.

CHALHUB, T.; GOMES, M. Museus como atividade educativa: o que pensam os alunos surdos sobre acessibilidade? In: ENCONTRO NACIONAL DE PESQUISA EM CIÊNCIA DA INFORMAÇÃO. Londrina, 19, 2018, p. 58065826. Anais [...], Londrina: ENANCIB, 2018. Disponível em: http://enancib.marilia.unesp.br/index.php/XIX_ENANCIB/xixenancib/paper/view File/1172/1754. Acesso em: 10 jun. 2020.

CIANTELLI, A. P. C.; LEITE, L. P. Ações Exercidas pelos Núcleos de Acessibilidade nas Universidades Federais Brasileiras. Revista Brasileira de Educação Especial, Marília, v. 22, n. 3, p. 413-428, Jul./Set., 2016.

CUNHA, M. B. Desafios na construção de uma biblioteca digital. Revista Ciência da Informação, Brasília, v. 28, n. 3, p. 257-268, set./dez. 1999.

CUNHA, M. B. Das bibliotecas convencionais às digitais: diferenças e convergências. Perspectivas em Ciência da Informação, Belo Horizonte, v. 13, n. 1, p. 2-17, jan./abr. 2008.

DICIONÁRIO HOUAISS. Acessibilidade. 13 ago. 2018. Disponível em: https://houaiss.uol.com.br/pub/apps/www/v3-3/html/index.php\#1. Acesso em: 13 ago.2018.

FARIA-NASCIMENTO, S. P. Representações lexicais da Língua de Sinais Brasileira: uma proposta lexicográfica. 2009. 325 f. Tese (Doutorado em Linguística) - Departamento de Linguística, Português e Línguas Clássicas, Universidade de Brasília, Brasília, 2009.

FELIPE, T. A. Libras em Contexto: curso básico - livro do estudante. 8 ed., Rio de Janeiro: WalPrint Gráfica e Editora, 2007.

FERREIRA, E. B. A.; CRUZ, R. W. R.; SANTOS, I. R. Acessibilidade nos sítios de Instituições Federais de Ensino Superior do Brasil: Uma análise por meio do AcessMonitor. In: ENCONTRO NACIONAL DE ENSINO E PESQUISA EM INFORMAÇÃO, 13., 2017, Salvador, BA. Anais [...], Salvador, BA: UFBA, 2017, p. 10-23. Disponível em:

http://www.cinform2017.ufba.br/modulos/gerenciamentodeconteudo/docs/366 anais\%2027_02_cinform.pdf. Acesso em: 08 set. 2018. 
FLICK, U. Introdução à pesquisa qualitativa. Tradução: Joice Elias Costa. $3^{\text {a }}$ ed. Porto Alegre: Artmed, 2009.

GALVÃO, L. S.; SANTOS, I. F. S.; SANTOS, M. C. Acessibilidade na Biblioteca Anísio Teixeira (BAT): as ações do Setor de Atendimento a Criança e ao Adolescente Surdo (SACAS). In: SEMINÁRIO NACIONAL DE BIBLIOTECAS BRAILLE, 8., 2014, São Paulo, SP. Anais [...], São Paulo, SP: FEBAB, 2014. Disponível em: https://rbbd.febab.org.br/rbbd/article/view/333. Acesso em: 30 ago. 2018.

GOMES, C. A. S. Direito à informação do surdo: usabilidade e acessibilidade nos espaços virtuais de bibliotecas universitárias federais brasileiras. 2013. 163f. Dissertação (Mestrado em Ciência da Informação) - Instituto de Arte e Comunicação Social, Universidade Federal Fluminense, Rio de Janeiro, 2013.

INCLUSIVE: inclusão e cidadania. Novo símbolo da acessibilidade. 04 ago. 2015. Disponível em: http://www.inclusive.org.br/arquivos/28238. Acesso em: 10 jan. 2019.

INTERNATIONAL FEDERATION OF LIBRARY ASSOCIATIONS AND INSTITUTTIONS. IFLA. Diretrizes para serviços de biblioteca para surdos. 2. ed. 2000. Série Publicações Ocasionais, n. 1. São Paulo, A Escola do Futuro, Universidade de São Paulo. (IFLA Professional Reports: 62). Disponível em: http://especial.futuro.usp.br/documentos/guiaifla.rtf. Acesso em: 08 set. 2018.

KAFURE, I.; ROCHA, S.; RODRIGUES, V.; SOUZA, A.; BASTOS, K.; RAPOSO, P.; MALHEIROS, T.; BOERES, S.; FEITOSA, A. A terminologia no estudo do usuário da informação. Biblios, Brasília, n. 51, p. 1-19, 2013.

MARQUES, R. R. Educação de Jovens e Adultos: um diálogo sobre a educação e o aluno surdo. In: QUADROS, R. M.; PERLIN, G. (Orgs.). Estudos Surdos II. Petrópolis: Editora Arara Azul, 2007, p. 132-149.

MARTINS, L. M. N.; LINS, H. A. M. Tecnologia e educação de surdos: possibilidades de intervenção. Nuances: estudos sobre Educação, Presidente Prudente, v. 26, n. 2, p. 188-206, maio/ago. 2015.

MIGLIOLI, S.; SANTOS, G. A.; Acessibilidade e serviços inclusivos para minorias sociais: a biblioteca do Instituto Nacional de Educação de Surdos.

Revista ACB: Biblioteconomia em Santa Catarina, Florianópolis, v. 22, n. 1, p. 136-149, dez./mar. 2017.

MIRANDA, S. N.; MIRANDA, M. L. C. Bibliotecas universitárias e a acessibilidade aos usuários surdos e com deficiência auditiva.

Informação@Profissões, Londrina, v. 4, n. 2, p. 04-19, jul./dez. 2015.

MIRANDA, S. N.; COSTA, M. V. S. B.; SILVA, M. M. O usuário surdo e a acessibilidade no sistema de bibliotecas da Unirio. Revista Brasileira de 
Biblioteconomia e Documentação, São Paulo, v. 13, n. esp., p. 2008-2019, 2017.

PAIVA, R. O.; BENCHIMOL, A.; CHALHUB, T.; FURTADO, C. C. Breves apontamentos sobre um repositório digital bilingue (Português-Libras): o caso do repositório digital Huet. Informação \& Sociedade: Estudos, João Pessoa, v. 29, n. 1, p. 101-116, jan./mar. 2019.

PIVETTA, E. M.; SAITO, D. S.; ULBRICHT, V. R. Surdos e Acessibilidade: Análise de um Ambiente Virtual de Ensino e Aprendizagem. Revista Brasileira de Educação Especial, Marília, v. 20, n. 1, p. 147-162, jan./mar. 2014.

QUADROS, R. M. 0 tradutor e intérprete de língua brasileira de sinais e língua portuguesa. Secretaria de Educação Especial; Programa Nacional de Apoio à Educação de Surdos. Brasília: Ministério da Educação, 2004.

QUADROS, R. M.; KARNOPP, L. B. Língua de sinais brasileira: estudos linguísticos. São Paulo: Artmed, 2004.

SALTON, B. P.; DALL AGNOL, A.; TURCATTI, A. Manual de Acessibilidade em documentos digitais. Bento Gonçalves, RS: Centro Tecnológico de Acessibilidade, 2017.

SANTOS, S. K. S. L.; SILVA, T. C.; KAFURE, I. Tecnologias digitais e acesso à informação: uma pesquisa com pessoas surdas. Revista ACB: Biblioteconomia em Santa Catarina, Florianópolis, v. 24, n. 1, p. 129-143, dez./mar. 2019.

SANZ CASADO, E. La realización de estudios de usuarios: una necesidad urgente. Revista General de Información y Documentación, Madrid, v. 3, n. 1, p. 154-166, 1993.

SASSAKI, R. K. Terminologia sobre Deficiência na Era da Inclusão. Mídia e Deficiência - Agência de Notícias dos Direitos da Infância e da Fundação Banco do Brasil. Brasília, p. 160-165, 2002.

SONZA, A. P.; FÉO, F.; PAGANI, J. Necessidades Educacionais Especiais. In: SONZA, A. P.; KADE, A.; FAÇANHA, A.; REZENDE, A. L. A.; NASCIMENTO, G. S.; ROSITO, M. C.; BORTOLINI, S.; FERNANDES, W. L. (Org.).

Acessibilidade e tecnologia assistiva: pensando a inclusão sociodigital de PNEs. Bento Gonçalves, RS: IRFS, Campus Bento Gonçalves, 2013, p. 67155. (Série Novos Autores da Educação Profissional e Tecnológica). Disponível em: https://cta.ifrs.edu.br/livro-acessibilidade-e-tecnologia-assistiva-pensandoa-inclusao-sociodigital-de-pessoas-com-necessidades-especiais/. Acesso em: 15 jan. 2020.

TOJAL, A. P. F. Comunicação museológica e ação educativa inclusiva: mudança de paradigmas. In: CARDOSO, E.; CUTY, J. (Orgs). Acessibilidade em Ambientes Culturais: relatos de experiências. Porto Alegre: Marcavisual, p. 14-33, 2014. 
TORRES, E. F.; MAZZONI, A. A.; ALVES, J. B. M. A acessibilidade à informação no espaço digital. Ciência da Informação, Brasília, v. 31, n. 3, p. 83-91, 2002.

UNIVERSIDADE FEDERAL DE MINAS GERAIS. UFMG. Símbolo Acessível em Libras. Set. 2013. Disponível em:

https://www.ufmg.br/marca/libras/\#variacoes. Acesso em: 10 jan. 2019.

\title{
DEAF USERS AND ACCESSIBILITY IN LIBRARY: A REVIEW OF BRAZILIAN SCIENTIFIC LITERATURE
}

\begin{abstract}
Introduction: new technologies and the internet promote changes in access to information and communication between people. Deaf users are part of a group that needs attention to meet their information needs. Objective: to present a literature review of Brazilian publications that address the relationship between deaf users and the library characterized by accessibility to information and communication. Methodology: exploratory and bibliographic research. Results: low number of publications related by the theme. Conclusions: need to increase the diffusion of sign culture and language in formal and non-formal spaces to promote deaf user care in their first language.
\end{abstract}

Descriptors: Deaf. Accessibility. Libraries. Literature review.

\section{USUARIOS SORDOS Y ACCESIBILIDAD EN LA BIBLIOTECA: UNA REVISIÓN DE LA LITERATURA CIENTÍFICA BRASILEÑA}

\begin{abstract}
RESUMEN
Introducción: las nuevas tecnologías y Internet promueven cambios en el acceso a la información y la comunicación entre los sujetos. Los usuarios sordos se consideran parte de un grupo que necesita atención para satisfacer sus necesidades de información. Objetivo: presentar una revisión de la literatura de publicaciones brasileñas que aborde la relación entre los usuarios sordos y la biblioteca caracterizada por la accesibilidad a la información y la comunicación. Metodología: investigación exploratoria y bibliográfica. Resultados: escaso número de publicaciones que abordan el tema. Conclusiones: necesidad de una mayor difusión del lenguaje de signos y la cultura en espacios formales y no formales para promover la atención de los usuarios sordos en su primer idioma.
\end{abstract}

Descriptores: Sordo. Accesibilidad. Bibliotecas. Revisión de literatura.

Recebido em: 16.01.2020

Aceito em: 10.06.2020 